\title{
Social and Economic Factors Influencing Buruli Ulcer Health Seeking Decision Making in the Ga West and South Municipalities
}

\author{
Collins K. Ahorlu ${ }^{1 \#}$, Eric Koka ${ }^{1,2}$, Seth Kumordzi ${ }^{1}$, Dorothy Yeboah-Manu ${ }^{1}$, \\ Edwin Ampadu ${ }^{3}$ \\ ${ }^{1}$ Noguchi Memorial Institute for Medical Research, University of Ghana, Legon, Ghana \\ ${ }^{2}$ School of Public Health University of Ghana, Legon, Ghana \\ ${ }^{3}$ National Buruli Ulcer Control Programme, Ghana Health Service, Accra, Ghana \\ Email: "cahorlu@noguchi.mimcom.org \\ Received July $7^{\text {th }}, 2013$; revised August $7^{\text {th }}, 2013$; accepted August $15^{\text {th }}, 2013$
}

\begin{abstract}
Copyright (C) 2013 Collins K. Ahorlu et al. This is an open access article distributed under the Creative Commons Attribution License, which permits unrestricted use, distribution, and reproduction in any medium, provided the original work is properly cited.
\end{abstract}

\begin{abstract}
Background: Buruli ulcer infection is generally referred to as a re-emerging disease with the highest burden in West Africa. In Ghana, about 1000 cases are reported annually. The former Ga district (now the Ga West and Ga South municipalities) continues to report the highest proportion of the worst ulcerated wounds in Ghana, despite various interventions implemented. The aim of this study was to determine factors affecting treatment-related decision making in BU affected families. Methods: Semi-structured questionnaire interview was conducted with 33 patients ( $\geq 15$ years) and seven caretakers of children aged below 15 years to determine the social and economic factors influencing BU-related health seeking decision making and types of treatment choices that are made. Results: Respondents were afflicted with varied categories of the disease (category one $(30 \%)$, category two $(35 \%)$ and category three $(35 \%)$ ). Decisions to seek health care from biomedical facilities are influenced by factors such as advice from health workers $(45.0 \%)$ and advice from family members $(42.5 \%)$. Only a quarter $(25 \%)$ of respondents actually mentioned "financial considerations" as one of the factors that influence their decision to seek for biomedical care. Whereas there was no significant relationship between family involvement in treatment decision making and category one $(p=0.5351)$ lesion, there was a significant relationship between family involvement in treatment decision making and categories two $(p=0.0434)$ and three $(p=0.0089)$ lesions. Conclusion: It appears from this study that financial consideration, which has been widely cited as a cause of treatment delay may be losing its influence to social factors. With the advent of free antibiotics treatment more studies are needed to identify social factors affecting BU treatment decision making so as to redesign health promotion messages appropriately, especially those aimed at getting patients into early treatment.
\end{abstract}

Keywords: Buruli Ulcer; Treatment Decision Making; Ghana; Socioeconomic

\section{Introduction}

Buruli ulcer (BU) infection is generally referred to as a reemerging disease with the highest burden in West Africa. In West Africa, BU prevalence in some village communities is more than tuberculosis (Debacker et al., 2006). The infection is known to be more prevalent among children aged 15 years and below (Van der Werf et al., 2005; Johnson et al., 2005; Sizaire et al., 2006; WHO, 2008; Ahorlu et al., 2013). The disease typically begins as a painless nodule under the skin or may manifest as a papule rather than the firm, painless nodule in some geographical areas. Over time, the nodule gradually enlarged and erodes through the skin surface, leaving a well-demarcated ulcer with a necrotic slough in the base with widely undermined

\footnotetext{
*Competing interests: The authors declare that they have no competing interest.
}

${ }^{\#}$ Corresponding author. edges, which is the hallmark of the disease. BU is an infection with very low case fatality but it could cause a great deal of morbidity and disability among sufferers (Van der Werf et al., 2005; Johnson et al., 2005; Sizaire et al., 2006; Ahorlu et al., 2013).

$\mathrm{BU}$ is caused by the environmental pathogen mycobacterium ulcerans. The mode of transmission of this pathogen has eluded researchers up to date, and as we wait to understand how the infection is transmitted, there is the need to understand social and economic factors affecting access to effective early treatment among patients and in affected families. Stienstra and colleagues have reported that financial difficulties were contributing to delay in treatment seeking among BU patients (Stienstra et al., 2002). Also, Ahorlu and colleagues have aptly demonstrated that it is essential to remove impediments that limit access to early effective treatment by implementing social interventions such as the provision of transportation to and 
from treatment centres on daily basis. It has been further established that early case detection is enhanced by organizing community outreach and screening activities in endemic villages (Ahorlu et al., 2013; Ackumey et al., 2011). Despite all these efforts, many patients still report late for diagnosis and treatment with severe ulcers coupled with disabilities. The question then is "what social and economic factors are considered when making decisions to seek for biomedical treatment at the clinic/ hospital in the Ga West and South Municipalities in Ghana?" This question has become important because some of the cases identified during community outreach and screening activities have not reported at health facilities for diagnosis and treatment, despite the provision of free transportation and snacks to patients who attend clinics on daily basis in part of our study area.

Most social science researches on BU have recommended health education to promote access to health care for BU patients. This position was clearly captured by Ackumey and colleagues (2011), when they stated, "intensifying health education and surveillance will create awareness and encourage early treatment. The question is, what kinds of issues are to be addressed in the health education? If it is the usual messages of asking people to take action without building their capacities to take the expected action, then our massages are less likely to succeed because the reality is that there is always a gap between knowledge and practice. The decision to do something is not only influenced by knowledge but also the ability to be able to do it, and this position was aptly captured by Farmer, when he said "all over the world those who do not comply are those least able to comply" (Farmer, 1999). This emphasizes the fact that knowing what to do is independent of having the capacity to do it appropriately. Therefore, social science research in BU must begin to identify barriers that require interventions in order to enhance the capacity of affected families and infected individuals to be able to access effective health care for the management of the disease early to avoid disabilities (Ahorlu et al., 2013).

$\mathrm{BU}$ is endemic in Ghana and about 1000 cases are reported annually, a nationwide prevalence of 20.7/100,000 population in 1998. However, prevalence varies across districts and that of the former Ga district (now the Ga West and Ga South municipalities) where this study took place was $87.7 / 100,000$ population making it the fifth most endemic in the country (Amofa et al., 2002). Until 2006, BU was treated in Ghana mainly by surgical interventions in centralized health facilities (hospitals), until WHO recommended the use of oral rifampicin $(10 \mathrm{mg} / \mathrm{kg})$ plus intramuscular streptomycin injection $(15 \mathrm{mg} / \mathrm{kg})$ for $\mathrm{BU}$ treatment. Both antibiotics are given daily for 8 weeks under supervision. Although daily injections for eight weeks is not a pleasant experience to go through, it has proven to be very effective in curing BU patients effectively, especially when accessed at an early stage of the disease (Sizaire et al., 2006; WHO, 2008; Etuaful et al., 2005). However, the Ga West and South municipalities continue to report the highest proportion of the worst ulcerated wounds in Ghana, despite various interventions implemented in the municipalities. Since the ability to access appropriate health care is influenced by the household therapy management group, this study was designed to identify the social and economic factors that are considered when making BU-related health seeking decision at the household level. Findings from this could inform the design and implementations of interventions that will facilitate household decision making process to promote early and effective BU treatment to reduce morbidity and disabilities among sufferers.

\section{Methods}

\section{Ethics Statement}

The Institutional Review Board of the Noguchi Memorial Institute for Medical Research, University of Ghana, reviewed the study. Each participant/caretaker was informed of the objectives, methods, anticipated benefits and potential hazards of the study. Participants/caretakers were also informed that they were at liberty to withdraw from the study at any time without penalty. They were assured that all information collected for the study would be kept confidential, and that in any resulting publication it would not be possible to link the data to individuals and families in the study. Written inform consent was obtained from all participants and none have declined participation in the study. Participants signed/thump print the consent form together with a witness to accept participation in the study. Consent was sought from the caretakers of children under 18 years before interview was conducted. However, at the point of interview, oral permission was sought from children (15 - 18 years) whose caretakers gave consent on their behalf to ensure that they do not feel coerce to participate in the study.

\section{Study Area}

The study was conducted in Ga West and South municipalities which together have an estimated population of 748,385 (Ghana Statistical Service, 2012). The municipalities have large peri-urban settlements due to their proximity to Accra, the national capital. The two municipalities are highly endemic and together continue to account for a large proportion of the severe ulcerated BU cases in Ghana (Ahorlu et al., 2013).

\section{Study Design and Data Collection}

This was a descriptive study designed to determine the social and economic factors influencing BU-related health seeking decision making and types of treatment choices that are made in the Ga West and South municipalities. Semi-structured questionnaire interviews were conducted with $37 \mathrm{BU}$ patients and seven caretakers of children less than 15 years attending a weekly BU clinic at Amasaman hospital (Ga West) and Obom health centre (Ga South). (The choice of 15 years was informed by local definition of adulthood, where most 15 years and above were already independent, especially when they are not in school). Semi-structured questionnaire interview is a flexible way of generating both quantitative and qualitative data to complement each other in a descriptive study. This technique allows for the collection of detail qualitative information from respondents, probing important related issues as they came up concerning the topics of interest during interview sessions, while using the structure of the questionnaire to remain focus on topics of interest for the study. Study participants were all 40 patients attending a weekly clinical session at Amasaman hospital (25 patients) and Obon health centre (15 patients) with none refusing participation. The semi-structured questionnaire was pre-tested for consistency and reliability in a BU endemic village outside the study municipalities. Findings and experiences from the pre-testing were used to refine and clarify questions and filling instructions before commencement of the actual data collection. The second and third authors (EK and SK) 
conducted the interviews under the supervision of the first author (CKA). At all the sessions, one person acted as a note taker.

\section{Data Analysis}

The data was edited and cleaned before analysis was done in Epi Info (version 3.3.2) to generate descriptive statistics for presentation. Quantitative data generated from the semi-structured questionnaire interviews were entered into Epi Info data base for analysis. Qualitative data from open-ended questions were entered into a word processor (Microsoft Word) and imported into MAXqda in a format that allows automatic coding by interview items. The qualitative data was analysed to clarify social and economic factors influencing BU-related health seeking decision making and the treatment choices that are made. Variables of interest in the qualitative data-base were imported into MAXqda as selection variables. This allowed the performance of phenomenological analysis on relevant coded segments to select representative narratives for presentation.

\section{Results}

The social demographic characteristics of respondents are presented in Table 1. Briefly, 40 participants were interviewed, out of which $60 \%$ were males. The age of respondents ranged from 8 to 70 years with a mean $( \pm \mathrm{SD})$ age of 32.9 (17.7). A quarter $(25 \%)$ of respondents had no formal education and about a fifth $(20 \%)$ was still in school. Majority of the respondents were Christians and $57.5 \%$ of them were married. The people were engaged in three dominant occupations - farming, petty trading and sand winning. It was not however uncommon to see a farmer engaging in sand wining during the lean planting and harvesting seasons.

Respondents were afflicted with varied categories of BU at the time of this study (Category one (30\%), Category two (35\%) and category three $(35 \%))$. This is an indication that most patients still report at the health facility late, despite being aware that the infection could be managed or treated with biomedicine. Most (95\%) of the respondents said they feel accepted within their social environment and strive for good reputation in the community despite their disease status.

Decisions to seek health care from biomedical facilities are influenced by various factors and prominent among them were advice from health workers $(45.0 \%)$ and advice from family members $(42.5 \%)$. Only a quarter $(25 \%)$ of respondents actually mentioned 'financial considerations' as one of the factors that influences their decisions to seek for biomedical health (Table 2).

Chi Square test revealed that family members get involved in $\mathrm{BU}$ treatment decision making when the condition progressed from category one to two and three. Whereas there was no significant relationship between family involvement in treatment decision making and category one $(p=0.5351)$ lesion, there was a significant relationship between family involvement in treatment decision making and category two $(p=0.0434)$ and three $(0.0089)$ lesions. The following narratives illuminate the role of social and economic factors in the decision to seek for biomedical treatment among BU patients:

I was asked by health workers who came here to show us video that I should report at the school the following morning for screening but I did not go. At the time the wound was very
Table 1.

Social demographic characteristics of respondents.

\begin{tabular}{|c|c|}
\hline Variables & $n=40$ \\
\hline Sex Ratio Male:Female & $3: 2$ \\
\hline Mean age $( \pm \mathrm{SD})$ & $32.9(17.7)$ \\
\hline \multicolumn{2}{|l|}{ Education (\%) } \\
\hline No formal education & 25.0 \\
\hline Pupil/student & 20.0 \\
\hline Primary education & 42.5 \\
\hline Junior high school or higher & 12.5 \\
\hline \multicolumn{2}{|l|}{ Religion (\%) } \\
\hline Christian & 92.5 \\
\hline Moslem & 7.5 \\
\hline \multicolumn{2}{|l|}{ Ethnicity (\%) } \\
\hline Ga/Adangbe & 52.5 \\
\hline Ewe & 30.0 \\
\hline Akan & 15.0 \\
\hline Others & 2.5 \\
\hline \multicolumn{2}{|l|}{ Marital status (\%) } \\
\hline Married & 57.5 \\
\hline Singles & 30.0 \\
\hline Divorced/separated & 7.5 \\
\hline Co-habitation & 5.0 \\
\hline \multicolumn{2}{|l|}{ Employment status (\%) } \\
\hline Farming & 42.5 \\
\hline Petty trading & 25.0 \\
\hline Pupils/students & 20.0 \\
\hline Sand winning & 12.5 \\
\hline
\end{tabular}

small. Later, my wife told me to go to the clinic because the situation was getting worse, so I went and I was told to start treatment after I was tested (a middle aged man during an interview session at Obom).

You see, it is good to be told that your condition can be healed but without the support of your family members, you cannot cope with the treatment. Once you start the treatment, it becomes everyday affair until you are healed and this can affect your work and your children education. You definitely need someone to help take care of your family in your absence (a young lady during an interview session at Amasaman).

Overwhelming majority (97.5\%) said they have sought financial supports from close associates to assist them to seek for BU treatment at one point or the other. However, only $51.9 \%$ of the 39 respondents said they were successful in mobilizing some funds for BU related treatment or management activities. The two most common sources of financial support were Parents (46.2\%) and Spouses (38.5\%) (Table 3).

Relatives and friends were willing to support varied types of treatment and the three most common types reported were 
Table 2.

Social and economic factors influencing decision to seek health from the clinic/hospital".

\begin{tabular}{cc}
\hline Influencing factors & Frequency (\%) $\mathbf{n}=\mathbf{4 0}$ \\
\hline Health workers & $18(45)$ \\
Family members & $17(42.5)$ \\
Self motivation to seek help & $11(27.5)$ \\
Financial considerations & $10(25)$ \\
Peers/Friends & $8(20)$ \\
Fear of disability & $5(12.5)$ \\
\hline
\end{tabular}

"Multiple choices were allowed; Table sorted in column 2 on descending order.

Table 3.

Persons consulted for financial support for BU management ${ }^{*}$.

\begin{tabular}{cc}
\hline Persons consulted & Frequency (\%) $\mathbf{n}=\mathbf{3 9}$ \\
\hline Parents & $18(46.2)$ \\
Spouses & $15(38.5)$ \\
Other relatives & $7(17.9)$ \\
Religious Leaders & $3(7.7)$ \\
Friends/peers & $2(5.1)$ \\
Traditional healers & $1(2.6)$ \\
\hline
\end{tabular}

"Multiple choices were allowed; Table sorted in column 2 on descending order.

Biomedical treatment at the hospital/clinic (97.4\%), Self medication with biomedicine $(46.2 \%)$ and Self treatment with herbal preparations at home $(38.5 \%)$ (Table 4$)$.

I can tell you that without my parents, I could not have come here for treatment because I have two children who must be cared for and my parents, especially my mother is looking after them for me. They even give me money to buy bandages and other things that I need (a middle aged woman during an interview session at Amasaman).

So long as I remain in this hospital, I remain a burden on my spouse who, besides coming here to take care of me, is also running around for money to keep the family at home. Sometimes I feel for her but what can I do? (a middle aged man during an interview session at Amasaman).

About $65 \%$ of the respondents admitted that they were teased or laughed at by some community members, especially those with big wounds that could be seen. Out of the 26 respondents who admitted being teased, 19 (73.1\%) said they dare to speak out when they are being laughed at or teased by some community members. However, the remaining 7 (26.9\%) said they deliberately hide their BU related wounds from people so as to avoid being teased or laughed at by some community members. However, patients reportedly received social supports from their relative as represented in the following narratives:

My relatives are always encouraging me to endure whatever I am going through now and go through the treatment because my problems will come to an end one day. My mother always tells me that God will save me from all the insults and embarrassments that I suffer in school (a 15 years old school boy during an interview session at Obom).

My wife advices me to take care of my wounds and treat it
Table 4.

Types of treatment that relatives and friends were willing to support ${ }^{*}$.

\begin{tabular}{cc}
\hline Types of treatment & Frequency (\%) $\mathbf{n}=\mathbf{3 9}$ \\
\hline Attending the clinic/hospital & $38(97.4)$ \\
Self medication (biomedicine) & $18(46.2)$ \\
Herbal treatment at home & $15(38.5)$ \\
Visiting prayer camps & $6(15.4)$ \\
Consulting traditional healers & $3(7.7)$ \\
\hline
\end{tabular}

*Multiple choices were allowed; Table sorted in column 2 on descending order.

the way the nurses told me to treat it so as to avoid complications (a middle aged man during an interview session at Obom).

Less than half $(42.5 \%)$ said their spiritual and religious beliefs help them to cope with the BU infection, especially the wounds associated with it. However, $92.5 \%$ of respondents said they have someone to turn to seek for advice and support regarding the management of their BU infections when needed. Most of the 37 respondents who reported that they have people to consult for advice and support tend to their Spouses (51.3\%) and Parents (48.6\%) (Table 5).

Majority $(87.5 \%)$ of the BU sufferers interviewed reported that they actively seek for BU related information from the media to guide their treatment choices. They were of the view that most of the information that they get from the media were not of much benefit to them as most media reportage concentrated on showing their big wounds and presenting them as unhygienic people. Prominent sources of information reported were Television $(85.7 \%)$, Radio (11.4\%) and print media including Brochures (5.7\%). Some of the respondents saw people with wounds on TV but did not understand the messages accompanying them because they were in English. The following narratives indicate some of the information that respondents received from the media:

I saw on TV that people who swim and work in water and marshy areas are more likely to be infected with $B U$. They also said, those of us who have the disease are poor people living in dirty environments (a middle aged lady caretaker during an interview session at Amasaman).

I saw on TV that people who do not get treatment early will have their legs amputated. So there are people who have the wounds bigger than mine but will not like to come to the hospital because they do not want their legs to be amputated (a 21 years old lady during an interview session at Obom).

$I$ heard on radio that anyone with the signs of $B U$ should seek health early at the hospital because $B U$ is on the increase in Ghana (A middle aged man caretaker during an interview session at Amasaman).

They showed some people with big wounds like mine on the TV but I did not understand what was said about it because it was said in the English language (a middle aged lady during an interview session at Obom).

\section{Discussion}

This paper examines the factors influencing health seeking decision making in BU affected communities in the Ga South and West municipalities in Ghana. Most socio-cultural and economic studies on BU reported on local perceptions (beliefs, knowledge and attitudes), and social and economic burdens of 
Table 5.

Persons consulted for advice concerning BU related health seeking*.

\begin{tabular}{cc}
\hline Persons consulted & Frequency (\%) $\mathbf{n}=\mathbf{3 7}$ \\
\hline Spouses & $19(51.3)$ \\
Parents & $18(48.6)$ \\
Other relatives & $7(18.9)$ \\
Religious leaders & $4(10.8)$ \\
Peers/friends & $3(8.1)$ \\
Nurses & $2(5.4)$ \\
\hline
\end{tabular}

"Multiple choices were allowed; Table sorted in column 2 on descending order.

the disease to patients and their families (Ahorlu et al., 2013; Stienstra et al., 2002; Adamba \& Owusu, 2011; Peeters et al., 2008; Renzaho et al., 2007; Debacker et al, 2004; Aujoulat et al., 2003; Bigelow et al., 2002; Asiedu \& Atuaful, 1998). This paper on the other hand focused on identifying social and economic factors that are considered when the affected and infected are making health seeking decisions on where and when to seek for health. About a third (35\%) of the study participants was classified as having category three ulcers and this confirmed the proportionally high prevalence of severe ulcers in the study area compared to other endemic districts in Ghana (Ahorlu et al., 2013; Ackumey et al., 2011).

The finding that decisions to seek health from health facilities are being influenced mainly by health workers, and/or family members rather than financial considerations contradict what was reported by Stienstra and colleagues that financial consideration was a reason for delay treatment seeking among BU patients (Stienstra et al., 2002). The important roles that health workers are playing in influencing decision to seek for biomedical health care could be attributed to community outreach programmes that have been organised in some of the endemic communities where outreach team members are usually referred to as health workers by respondents. These outreach activities are not only perceived as coming from health workers but also provided information that assured community members that the disease could be effectively treated at health facilities in the two municipalities. During outreach activities, success stories are shared by former patients who have been successfully treated at the health facilities and this helped to boost community confidence in the health system to manage BU effectively (Ahorlu et al., 2013). Also, the importance of family members in decision making regarding BU treatment could be attributed to social pressure from the therapy management group. This pressure becomes stronger as the disease progresses from category one to two and three. This finding suggests that social factors are becoming more potent and important than financial factors in decision making to seek for biomedical care, especially when the disease progressed to cause real morbidity and disabilities.

The importance of spouses and parents in decision making regarding BU treatment cannot be overemphasized, as these were the two most consulted sources for both advice and financial supports for BU management. This is an indication that no meaningful BU-related health promotion or education can be done without the involvement of this important therapy management group members. It was encouraging to note that close associates contacted for financial assistance were overwhelm- ingly willing to support biomedical treatment at health facilities compare to other treatment sources. It must be emphasized that as biomedical treatment has become more available with improved rate of successful treatment outcomes and coupled with the willingness of family members and friends to support biomedical treatments, the role of traditional healers may become less important in BU management and this must be desired by all. This position supports the earlier report by Ahorlu and colleagues that traditional healers were not seeing as many patients as expected and that many reports misclassified home-based herbal therapy as treatments from traditional healers, hence their perceived significance in the management of BU (Ahorlu et al., 2013). They argue further that traditionally, every home in Ghana and for that matter Africa, know one or two herbs that are used for wound management and it is the use of these home-prepared herbal therapy that has been attributed to traditional healer to make them appear very important in BU management (Ahorlu et al., 2013). There is however the need to continue to improve access to early effective treatment for BU patients to demystify the "mystery" surrounding the disease to a point where it becomes a matter of course to report at the health facility for free antibiotic treatment for BU in endemic communities.

Findings confirmed what has been reported by others that BU patients, especially those with severe ulcerated wounds suffer some degree of stigmatization in their communities (Stienstra et al., 2002; Adamba \& Owusu, 2011; Peeters et al., 2008; Debacker et al., 2004; Aujoulat et al., 2003; Bigelow et al., 2002). In our study, about $65 \%$ of the respondents alluded to the fact that they were teased or laughed at by some community members. Though, some of them said they dare to speak out when they are being humiliated by others, this situation may affect the health seeking behaviour of patients as they may try to hide their condition to avoid being ridiculed or teased by non-affected community members.

Although, respondents reportedly sought for BU-related information from the media, they were not happy about how BU cases were presented in the media; they were presented as unhygienic people. This negative media reportage may be promoting BU-related stigmatization, which may cause patients to conceal their infections till they could no longer conceal it or bear with the pains. In effect, the negative media reportage may contribute to late health seeking. There is therefore a need to improve media reportage to provide information on treatment options available and where affected communities and individuals could seek for effective health care. The media must place emphasis on messages that demystify the infection as a mystery disease by reassuring affected communities that the infection could be treated effectively at the health facilities, where the treatment drugs are free. The media must therefore focus on the positive aspect of disease control by taking their audience through the treatment process, showing success stories of those who were treated effectively and were cured of the disease. BU control programme implementers should take advantage of the media by collaborating with media houses, especially the public television station to show local documentaries with treatment success stories and the benefits of early treatment.

\section{Conclusion}

It appears from this study that financial consideration, which has been widely cited as a cause of treatment delay may be 
losing its influence to social factors. With the advent of free antibiotics treatment we need to explore and identify social factors that may be affecting BU treatment decision making so as to redesign our health promotional messages appropriately, especially those targeted at getting patients into early treatment (Stienstra et al., 2002; Adamba \& Owusu, 2011). There is the need for more health promotional activities in endemic communities emphasizing the availability of effective treatment for $\mathrm{BU}$ at health facilities. There is also a need to involve endemic communities in the biomedical therapy management process, so as to encourage the use of social pressure from family members and friend to get patients into early treatment to avoid disabilities. It appears that traditional healers are losing their grip on BU patients and this must be sustained by roping them into early case detection and referral to health facilities, in this way, they may feel that they are being recognized and therefore do nothing to reverse the current progress.

\section{Acknowledgements}

We are grateful to the Ga South and West Municipal health directorates for collaborating with us on this study. We sincerely thank the chief and people of the study communities for their support. We also thank our respondents both the infected and the affected who share their experiences with us by participated in the study, without them there will be no study. We sincerely thank the staff of the Obom health centre and the Amasaman Hospital for their collaborations.

\section{REFERENCES}

Ackumey, M. M., Kwakye-Maclean, C., Ampadu, E. O., de Savigny, D., \& Weiss, M. G. (2011). Health services for Buruli ulcer control: Lessons from a field study in Ghana. PLoS Neglected Tropical Diseases, 5, e1187. doi:10.1371/journal.pntd.0001187

Adamba, C., \& Owusu, A. Y. (2011). Burden of Buruli ulcer: How affected households in a Ghanaian District cope. African Study Monographs, 32, 1-23.

Ahorlu, C. K., Koka, E., Yeboah-Manu, D., Lamptey, I., \& Ampadu, E. (2013). Enhancing Buruli ulcer control in Ghana through social interventions: A case study from the Obom sub-district. BMC Public Health, 13, 59. doi:10.1186/1471-2458-13-59

Amofa, G., Bonsu, F., Tetteh, C., Okrah, J., Asamoah, K., Asiedu, K., $\&$ Addy, J. (2002). Buruli ulcer in Ghana: Results of a national case search. Emerging Infectious Diseases, 8, 167-170. doi:10.3201/eid0802.010119

Asiedu, K., \& Etuaful, S. (1998). Socioeconomic implications of Buruli ulcer in Ghana: A three-year review. American Journal of Tropical Medicine and Hygiene, 59, 1015-1022.
Aujoulat, I., Johnson, C., Zinsou, C., Guédénon, A., \& Portaels, F. (2003). Psychosocial aspects of health seeking behaviours of patients with Buruli ulcer in southern Benin. Tropical Medicine and International Health, 8, 750-759. doi:10.1046/j.1365-3156.2003.01089.x

Bigelow, J., Welling, R., Sinnott, R., \& Evenson, R. (2002). Attitudes toward clinical and traditional treatment for Buruli ulcer in the $\mathrm{Ga}$ district, Ghana. Annals of African Medicine, 1, 99-111.

Debacker, M., Aguiar, J., Steunou, C., Zinsou, C., Meyers, W. M. et al. (2004). Mycobacterium ulcerans disease: Role of age and gender in incidence and morbidity. Tropical Medicine \& International Health, 9, 1297-1304. doi:10.1111/j.1365-3156.2004.01339.x

Debacker, M., Portaels, F., Aguiar, J., Steunou, C., Zinsou, C. et al. (2006). Risk factors for Buruli ulcer, Benin. Emerging Infectious Diseases, 12, 1325-1331. doi:10.3201/eid1209.050598

Etuaful, S., Carbonnelle, B., Grosset, J., Lucas, S., Horsfield, C., Phillips, R., Evans, M., Ofori-Adjei, D., Klutse, E., Owusu-Boateng, J., Amedofu, G. K., Awuah, P., Ampadu, E., Amofah, G., Asiedu, K., \& Wansbrough-Jones, M. (2005). Efficacy of the combination rifampinstreptomycin in preventing growth of Mycobacterium ulcerans in early lesions of Buruli ulcer in humans. Antimicrobial Agents and Chemotherapy, 49, 3182-3186. doi:10.1128/AAC.49.8.3182-3186.2005

Farmer, P. (1999). Infections and inequalities: The modern plagues. California: University of California Press.

Ghana Statistical Service (2012). 2010 population and housing census. Accra.

Johnson, P. D., Stinear, T., Small, P. L., Pluschke, G., Merritt, R. W., Portaels, F., Huygen, K., Hayman, J. A., \& Asiedu, K. (2005). Buruli ulcer (M. ulcerans infection): New insights, new hope for disease control. PLoS Medicine, 2, e108. doi:10.1371/journal.pmed.0020108

Peeters, G. K., Um Boock, A., Peeters, H., Hausmann-Muela, S., Toomer, E. et al. (2008). "It is me who endures but my family that suffers": Social isolation as a consequence of the household cost burden of Buruli ulcer free of charge hospital treatment. PLoS Neglected Tropical Diseases, 2, e321. doi:10.1371/journal.pntd.0000321

Renzaho Andre, M.N., Woods Paul, V., Ackumey Mercy, M., Harvey Simon, K., \& Kotin, J. (2007). Community-based study on knowledge, attitude and practice on the mode of transmission, prevention and treatment of the Buruli ulcer in Ga West District, Ghana. Tropical Medicine and International Health, 12, 445-458. doi:10.1111/j.1365-3156.2006.01795.x

Sizaire, V., Nackers, F., Comte, E., \& Portaels, F. (2006). Mycobacterium ulcerans infection: Control, diagnosis, and treatment. The Lancet Infectious Diseases, 6, 288-296. doi:10.1016/S1473-3099(06)70464-9

Stienstra, Y., van der Graaf, W. T., Asamoa, K., \& van der Werf, T. S. (2002). Beliefs and attitudes toward Buruli ulcer in Ghana. American Journal of Tropical Medicine and Hygiene, 67, 207-213.

Van der Werf, T. S., Stienstra, Y., Johnson, R. C. et al. (2005). Mycobacterium ulcerans disease. Bulletin of the World Health Organization, 83, 785-791.

World Health Organization (2008). Buruli ulcer: Progress report, 20042008. Weekly Epidemiological Record, 83, 145-154. 